\title{
The Physical Design \\ of Integrated Passive Components Receiver \\ GNSS-Signals Based on the Technology \\ of Low-Temperature Ceramics
}

Vadim M. Karabana, Igor D. Zyrin', Sergey B. Suntsov ${ }^{\mathrm{b}}$ and Vadim N. Shkolniy

${ }^{a}$ Tomsk State University of Control Systems and Radioelectronics 40 Lenin Str., Tomsk, 634050, Russia

${ }^{b}$ «Information Satellite Systems» Academician M.F. Reshetnev 52 Lenin Str., Zheleznogorsk, Krasnoyarsk region, 662972, Russia

Received 02.03.2016, received in revised form 19.04.2016, accepted 17.05.2016

In terms of development of GNSS-signal receiver examines the physical design of integrated passive components on the basis of the low-temperature ceramic, such as a power divider, stripline, microstrip and the associated microstrip transmission line, bandpass filter capacitor resonator. As a result of the physical design model sample designed microwave multilayered IC LTCC.

Keywords: physical design, passive integrated components, multilayered integrated schemes, multichannel receiver of GNSS-signals, radionavigation, autonomous navigation, low-temperature ceramics, the band passing filter, capacitor, resonator, computational modeling, electromagnetic fields, S11 and S21 characteristics.

Citation: Karaban V.M., Zyrin I.D., Suntsov S.B., Shkolniy V.N. The physical design of integrated passive components receiver gnss-signals based on the technology of low-temperature ceramics, J. Sib. Fed. Univ. Eng. technol., 2016, 9(4), 513-522. DOI: 10.17516/1999-494X-2016-9-4-513-522.

(C) Siberian Federal University. All rights reserved

* Corresponding author E-mail address: karaban_vm@mail.ru 


\title{
Физическое проектирование
}

\author{
пассивных интегральных компонентов \\ приёмника ГНСС-сигналов
}

\section{на основе технологии низкотемпературной керамики}

\author{
В.М. Карабан ${ }^{a}$ И.Д. Зырин \\ С.Б. Сунцов ${ }^{\sigma}$, В.Н. Школьный

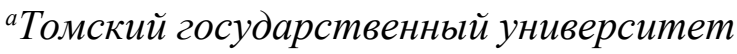 \\ систем управления и радиоэлектроники \\ Россия, 634050, Томск, пр. Ленина, 40

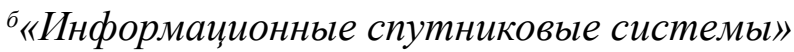 \\ имени академика М.Ф. Решетнёва
}

Россия, 662972, Красноярский край, Железногорск, ул. Ленина, 52

В части разработки приёмника ГНСС-сигналов рассматривается физическое проектирование пассивных интегральных компонентов на основе низкотемпературной керамики, таких как делитель мощности, полосковая, микрополосковая и связанная микрополосковая линии передачи, полосно-пропускающий фильтр, конденсатор, резонатор. По результатам физического проектирования разработан макетный образец СВЧ МИС НТК.

Ключевые слова: физическое проектирование, пассивные интегральные компоненты, многослойные интегральные схемы, многоканальный приёмник ГНСС-сигналов, радионавигаџия, автономная навигация, низкотемпературная керамика, полоснопропускающий фильтр, конденсатор, резонатор, вычислительное моделирование, электромагнитные поля, S11- и S21-характеристики.

Сегодня одной из актуальных задач является создание отечественной электронной компонентной базы для радиотехнических устройств и систем специального назначения, удовлетворяющей современным требованиям к функциональным возможностям работы в жёстких эксплуатационных условиях [1]. Решение этой задачи требуется, в частности, для реализации координатно-временного обеспечения космических аппаратов, полезная нагрузка которых включает активные и пассивные радиолокаторы, средства наблюдения и дистанционного зондирования, навигационные устройства и др.

Для исключения недостатков традиционных конструкций печатных плат, плат толстопленочных и тонкопленочных микросборок и плат на основе высокотемпературной керамики при реализации функционально насыщенных высокоскоростных и высокочастотных радиотехнических устройств и систем с уменьшенными массогабаритными показателями и себестоимостью изготовления, повышенной эффективностью и длительным (15 и более лет) сроком активного существования актуальна реализация сверхвысокочастотных (СВЧ) многослойных интегральных схем (МИС), выполняющих функции формирования (передатчик) и приёма (приёмник) сигналов глобальных навигационных спутниковых систем (ГНСС) нового поколения: ГЛОНАCC, NAVSTAR GPS, Galileo и Compass на основе низкотемпературной совместно-обжигаемой керамики (НTK) (английская аббревиатура LTCC - Low Temperature Co-fired Ceramics) [1]. 


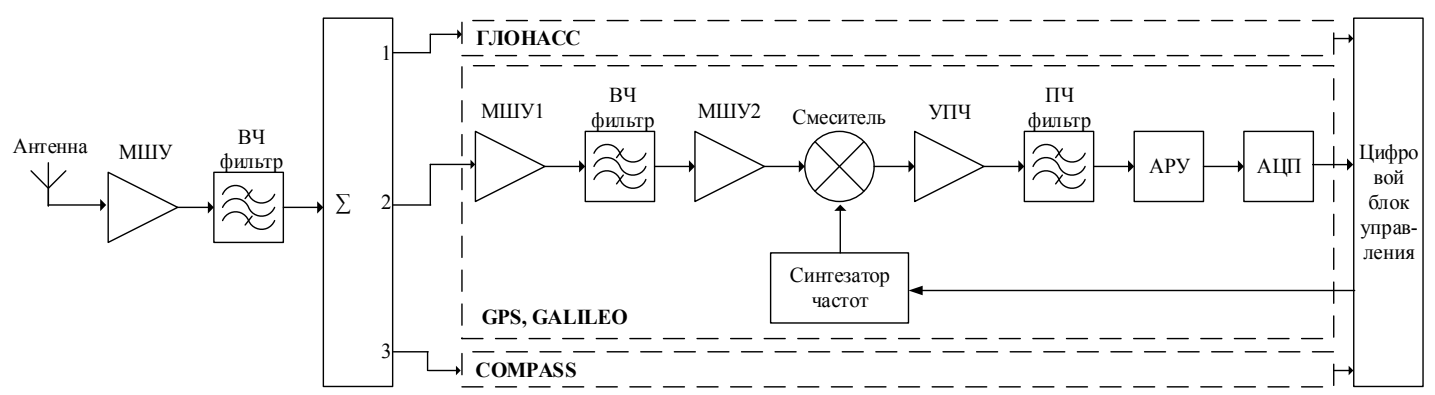

Рис. 1. Структура многоканального приёмника с частотным разделением ГНСС-сигналов

Приёмники радионавигационных систем, как и большинство приёмников средств связи, строятся по супергетеродинной схеме с однократным, двукратным и реже трёхкратным преобразованиями частоты [2, 3]. Достоинства супергетеродинных приёмников - возможность достижения высоких уровней коэффициента передачи на относительно низких частотах промежуточной частоты и обеспечение высокой избирательности по каналам промежуточной частоты, что весьма трудно осуществить на высоких частотах.

Структурная схема многоканального приёмника ГНСС-сигналов, реализуемого по супергетеродинному принципу с двукратным преобразованием частоты, включает в себя (рис. 1): полосовые фильтры, малошумящий усилитель (МШУ), смеситель, делитель, синтезатор частот, усилитель промежуточной частоты (УПЧ), аналогово-цифровой преобразователь (АЦП). Синтезатор частот, в свою очередь, состоит из генератора, управляемого напряжением (ГУН), системы фазовой автоподстройки частоты (ФАПЧ), опорного генератора и схемы управления. Управление синтезатора осуществляется с цифрового блока управления $[2,3]$.

\section{Технологии изготовления интегральных компонентов}

Для разработки активных компонентов ГНСС-приёмника для космического применения могут использоваться освоенные в настоящее время отечественные коммерческие полупроводниковые технологии изготовления СВЧ монолитно-интегральных схем (ЗАО «НПФ «Микран» (Томск), ОАО «НИИ ПП» (Томск), ОАО «Интеграл» (Минск), ОАО «НИИМЭ и Микрон» (Москва), ФГУП НПП «Исток» (Москва), АО «ПКК Миланд» (Москва), ИСВЧПЭ РАН (Москва) и др.), каждая из которых имеет свои конкурентные преимущества [2, 3]:

1) технологии на основе арсенида галлия GaAs. K ним относятся технологии полевых гетероструктурных транзисторов ТВПЭ (англ. НЕМТ - High Electron Mobility Transistor), пТВПЭ (англ. рНЕМТ) и мТВПЭ (mНЕМТ), а также технологии ГБТ (англ. НВТ - Heterojunction Bipolar Transistor);

2) технология полевых транзисторов КМОП (англ. CMOS - Complementary Metal-OxideSemiconductor) на основе кремния (Si), а также технология БиКМОП (англ. BiCMOS) на основе соединения кремний-германий ( $\mathrm{SiGe})$, объединяющая технологию биполярных транзисторов и КМОП-технологию.

ТВПЭ-технологии - это технологии для промышленного производства сравнительно недорогих аналоговых СВЧ монолитных интегральных схем массового применения (МШУ, УМ 
и др.). Гетероструктурные GaAs ТВПЭ-технологии весьма радиационно стойки. В частности, в [4] отмечается, что монолитные-интегральные схемы на основе GaAs пТВПЭ-технологии сохраняли работоспособность при величине накопленной дозы до 10000 кРад (воздействие гамма-излучения). Кроме того, они не подвержены одиночным эффектам от ТЗЧ (SEU, SEL).

C точки зрения реализации приёмников ГНСС главным недостатком GaAs ТВПЭтехнологий является отсутствие комплементарных транзисторов (например, аналогично транзисторам р- и n-типа в КМОП технологиях). Это очень затрудняет создание даже простых логических ячеек и практически исключает создание логических схем средней сложности; в результате на основе таких технологий невыполним такой важный узел приемников ГНСС, как синтезатор частоты. К другим существенным недостаткам GaAs TВПЭ-технологий, также затрудняющим их использование при создании приемников ГНСС, относятся: малая степень интеграции, связанная прежде всего со значительными размерами транзисторов; малая мак-

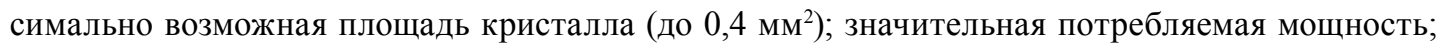
большая стоимость по сравнению с кремниевыми технологиями $[2,3]$.

Достоинством ГБТ технологии (в отношении ТВПЭ) служит бо́льшая пригодность для реализации простых логических схем, а также возможность интеграции с оптоэлектронными устройствами (фотодиодами и оптическими модуляторами). К недостаткам относится то, что ГБТ-технологии более дорогие и менее распространенные.

При создании СВЧ многослойных интегральных схем КМОП-технология имеет ряд достоинств по сравнению с ТВПЭ-технологиями: позволяет одновременно выполнить функции обработки аналоговых и цифровых сигналов в одном кристалле, т.е. реализовать концепцию «системы-на-кристалле» (СнК) (англ. SOC - System On a Chip); имеет меньшие размеры компонентов, в связи с чем допускает более плотную упаковку элементов; разрешает увеличить площадь кристалла (до $4 \mathrm{~cm}^{2}$ ) и может содержать большее число транзисторов на кристалле; кремниевые подложки могут иметь диаметр свыше 150 мм; кремниевые технологии значительно дешевле технологий на основе полупроводников GaAs и GaN [2-3].

Технология БиКМОП на основе материала $\mathrm{SiGe}$ предполагает изготовление на одной подложке ГБТ- и МОП-транзисторов (по КМОП-технологии). Она также использует кремниевую подложку и разрешает одновременно реализовывать аналоговые и цифровые функции. При этом технология БиКМОП сочетает достоинства КМОП-технологии (малое потребление мощности, высокая степень интеграции) и биполярной технологии (малые фазовые шумы, низкий коэффициент шума). В технологии БиКМОП ГБТ на основе SiGe более высокочастотные, чем кремниевые МОП-транзисторы в КМОП-технологии, их граничная частота может достигать 200 ГГц (при базовом размере 100 нм). Однако в связи с затратами при формировании ГБТ БиКМОП-технология дороже технологии КМОП.

В то же время технологии на основе материалов $\mathrm{Si}$ и $\mathrm{SiGe}$ имеют два значительных недостатка в сравнении с ТВПЭ-технологиями: 1) при одинаковой топологической норме КМОП- и БиКМОП-технологии уступают в значении предельной частоты ТВПЭ- и ГБТ-технологиям на базе соединения GaAs (рабочие частоты не превышают 40-60 ГГц); 2) в связи с меньшими значениями пробивных напряжений уровень сигнала на базе материалов $\mathrm{Si}$ и $\mathrm{SiGe}$ значительно ниже, поэтому эти технологии не могут применяться для создания усилителей с высокой выходной мощностью. 
Ещё одной проблемой при изготовлении СВЧ монолитно-интегральных схем на кремниевых подложках выступает значительно меньшее сопротивление Si по сравнению с GaAs, это приводит к уменьшению добротности и увеличению потерь в пассивных элементах (катушках индуктивности, конденсаторах, линиях передачи). Одним из выходов является использование на кремниевой подложке дополнительного изолирующего слоя $\mathrm{SiO}_{2}$ (технология КНИ), однако это усложняет и удорожает изготовление.

На основании вышесказанного можно отметить, что ряд аналоговых компонентов, таких как коммутаторы, МШУ, смеситель и ГУН, может быть разработан на основе GaAs пТВПЭтехнологий. Из-за малой степени интеграции GaAs-технологии разработка компонентов приёмников на её основе, как правило, осуществляется по принципу «один компонент на одном кристалле». В этом случае радионавигационный приёмник должен быть реализован на базе концепции «система-в-корпусе» (СвК). Но синтезатор частот и УПЧ с высоким коэффициентом усиления (до 70-100 дБ) должны быть реализованы на основе Si КМОП- или SiGe БиКМОПтехнологий [2-3].

В этой связи актуальна разработка на основе НТК следующих пассивных компонентов L1-диапазона частот: делитель мощности; полосно-пропускающий фильтр (ППФ); полосковая, микрополосковая и связанная микрополосковая линии передачи; индуктивности, конденсаторы; резонатор.

\section{Физическое проектирование}

\section{пассивных интегральных компонентов}

При физическом проектировании пассивных интегральных компонентов приёмника ГНСС-сигналов на первом этапе необходимо определить материалы, из которых они будут выполняться, а именно материал основания и материал сигнальных слоёв СВЧ МИС НТК. Диэлектрическое основание выполняется из керамики марки GreenTape 951PX (диэлектрическая проницаемость 7,8, тангенс диэлектрических потерь 0,006 , толщина одного спеченного листа равна 0,2159 мм). Сигнальные слои выполняются из серебряной пасты.

Физическое проектирование основано на расчете полосковой, микрополосковой и связанной микрополосковой линий передачи, поскольку их в дальнейшем можно применять для проектирования остальных компонентов. Принято решение применять два слоя основания между сигнальным и опорным проводником с общим волновым сопротивлением 50 Ом. В результате расчёта получились следующие конструктивные параметры линий передач:

- микрополосковая: ширина проводника 0,509 мм;

- полосковая: ширина проводника 0,214 мм;

- связанная микрополосковая: ширина проводников 0,608 мм, расстояние между проводниками 0,4 мм.

Для физического проектирования простейшего резонатора необходимо выполнить микрополосковую линию передачи длиной, равной четверти длины волны. В результате расчёта длина микрополоска составила 20,2323 мм.

Физическое проектирование делителя мощности основывалось на принципах кольцевых делителей [4]. Данный подход позволит добиться хороших показателей деления сигнала, а также за счёт установки 100-омного резистора получить достаточную развязку 
между выходами делителя. Поскольку делитель работает на частоте 1,6 ГГц и выполняется на основе СВЧ МИС НТК, то возможно выполнение четверти волновых плечей делителя в виде меандра. Данный подход позволит сократить габариты делителя, при этом сохранив его хорошие показатели. Результат проектирования делителя показан на рис. $2 a$. Поскольку вход и выход делителя 50-омные и расстояние между опорным слоем и проводящим рисунком составляет 0,44 мм, ширина проводников для входных и выходных сигналов выбирается аналогично 50-омной микрополосковой линии. Плечи делителя выполнены из 75-омных микрополосковых линий передачи длиной, равной четверти длины передаваемого сигнала.

Физическое проектирование ППФ выполнялось согласно методике [6-10]. Результат физического проектирования показан на рис. 26.

Конденсатор спроектирован в однослойном и многослойном исполнении (рис. 3).

\section{Вычислительное моделирование}

Для проведения вычислительного моделирования топологический рисунок рассматриваемых пассивных компонентов в интегральном исполнении транслирован в программное обеспечение ANSYS HFSS [11]. Для каждого моделируемого компонента была получена его
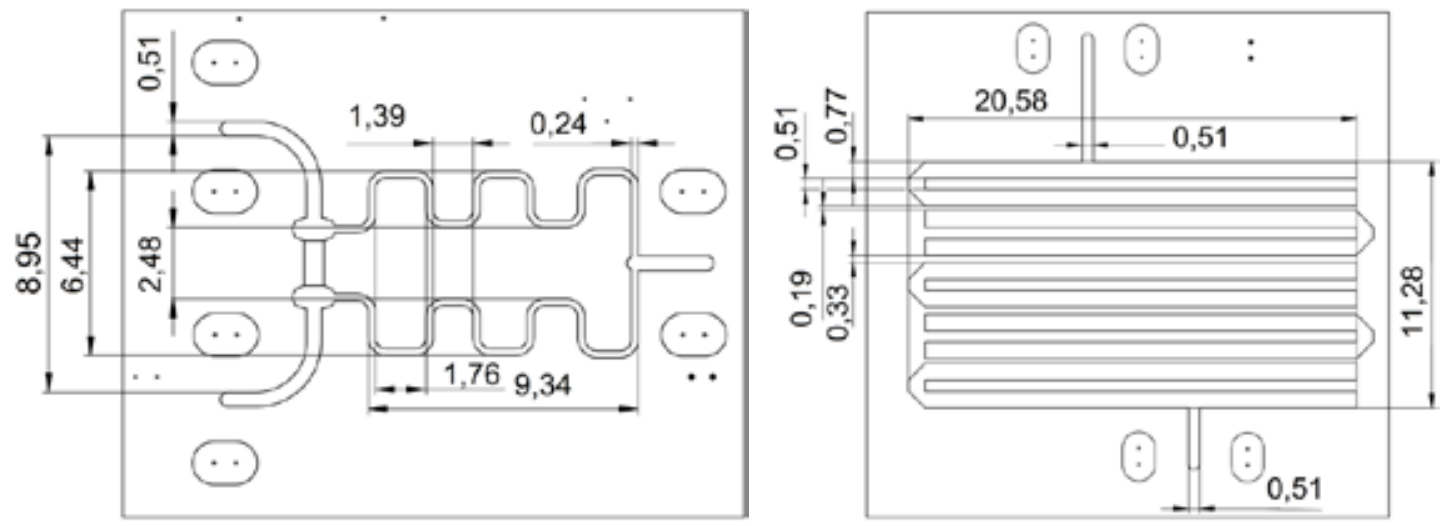

Рис. 2. Физическая структура СВЧ-делителя мощности (a) и ППФ (б)

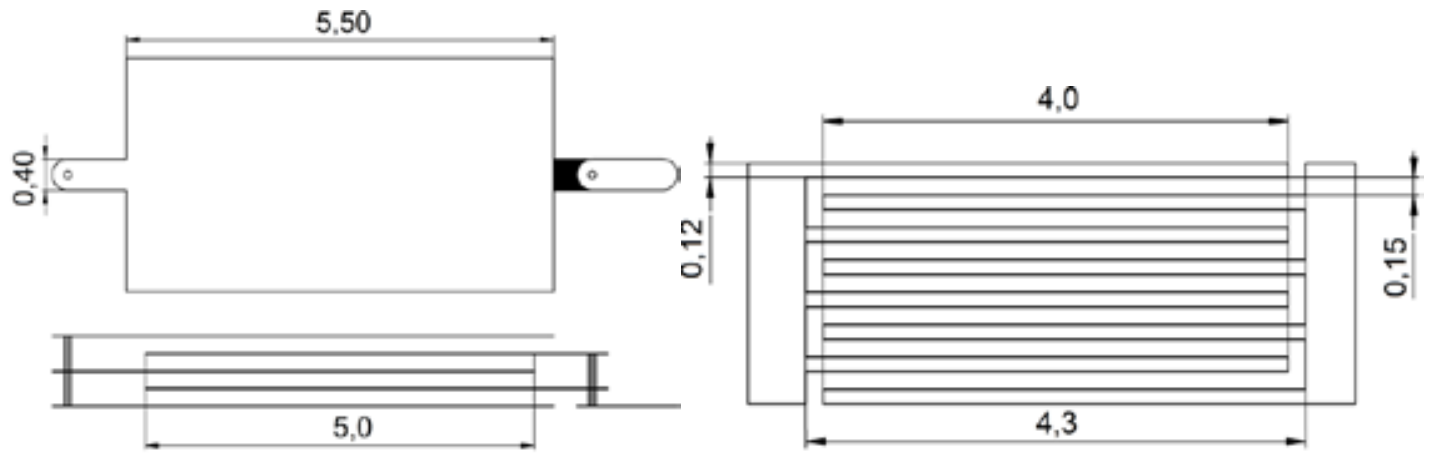

Рис. 3. Физическая структура конденсатора многослойного (слева) и однослойного (справа) 
конечно-элементная модель и проведен расчёт электромагнитного поля, после чего был проведён расчёт матрицы S-параметров.

Результаты расчёта S21- и S11-параметров для делителя показаны на рис. 4a, для ППФ - на рис. 46, для резонатора - на рис. 5, для полосковой линии - на рис. 6 .

Проведенное вычислительное моделирование и полученные S11- и S21-характеристики показали, что ППФ, делитель и полосковая линия хорошо подходят для работы на частоте 1,6 ГГц. Анализ результатов резонатора (рис. 5) демонстрирует, что резонансная частота получилась равной 1,5 ГГц вместо целевой 1,6 ГГц. В связи с этим для резонатора необходим параметрический перерасчёт длины. В результате параметризации было получено значение длины резонатора величиной 19,7323 мм, при которой S11 на частоте 1,6 ГГц имеет максимальное значение. S11- и S21харакетристики резонатора после параметрического перерасчёта представлены на рис. 7.

На основе результатов физического проектирования компонентов разработан макет СВЧ МИС НТК приёмника ГНСС-сигналов, реализуемого по принципу «система-в-корпусе» (рис. 8).

\section{Заключение}

Физическое проектирование пассивных интегральных компонентов, таких как делитель мощности, полосковая, микрополосковая и связанная микрополосковая линии передачи,
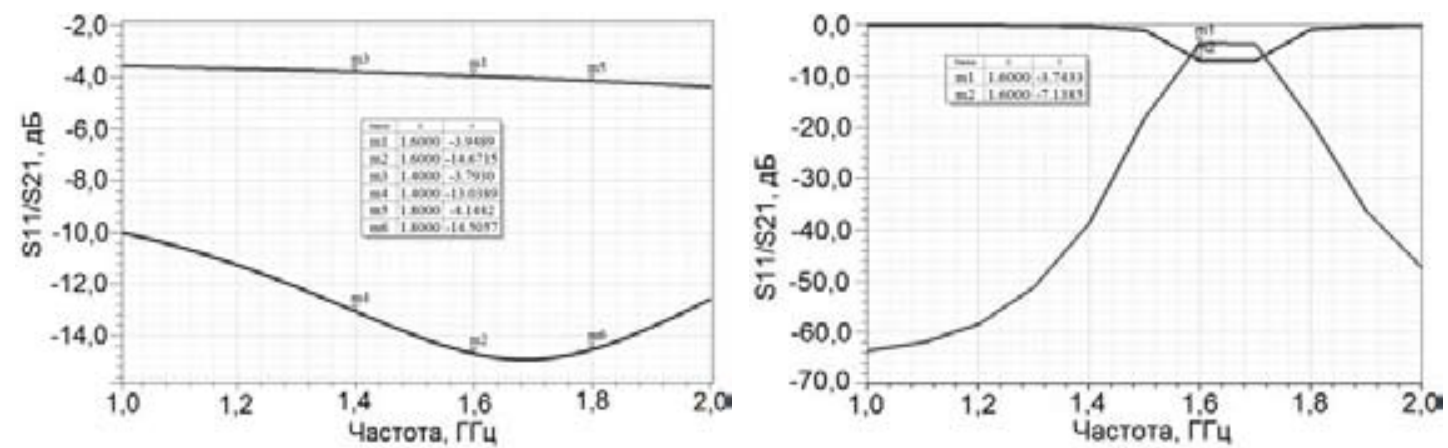

Рис. 4. S11- и S21-характеристики делителя мощности (a) и ППФ (б)
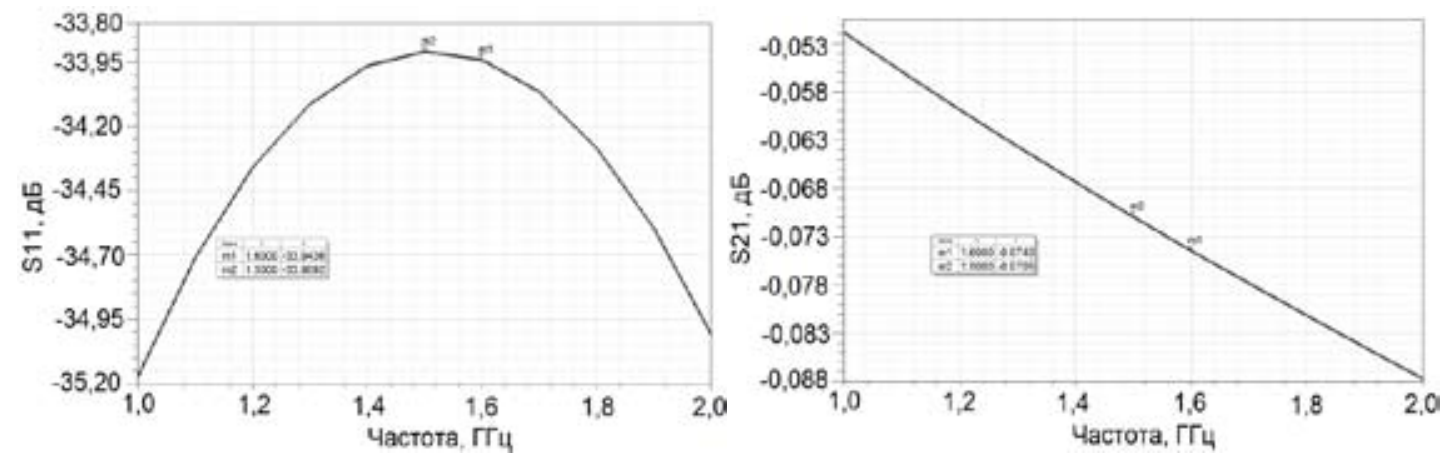

Рис. 5. S11- и S21-характеристики резонатора на микрополосковой линии 

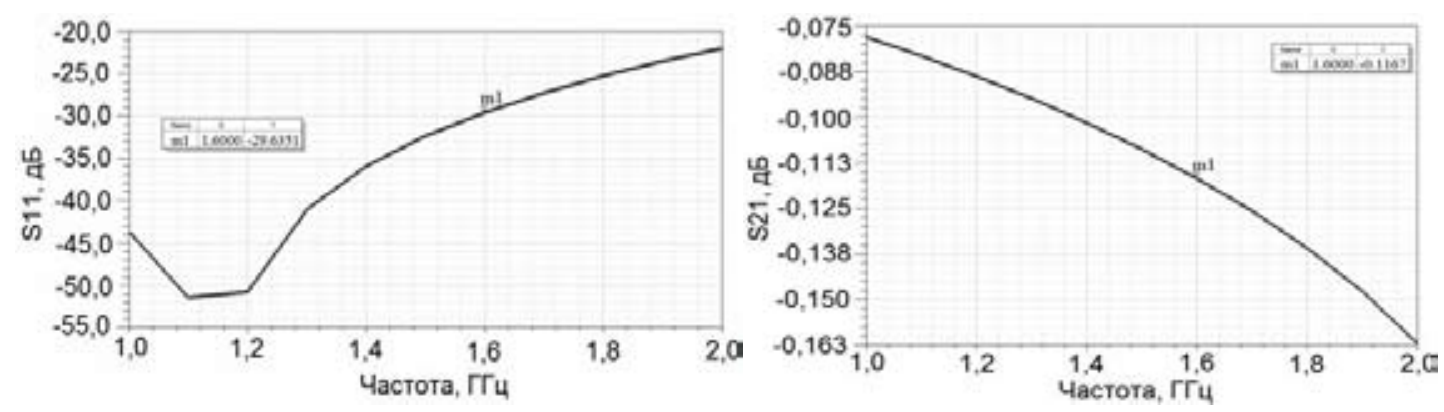

Рис. 6. S21- и S11-характеристики полосковой линии передачи
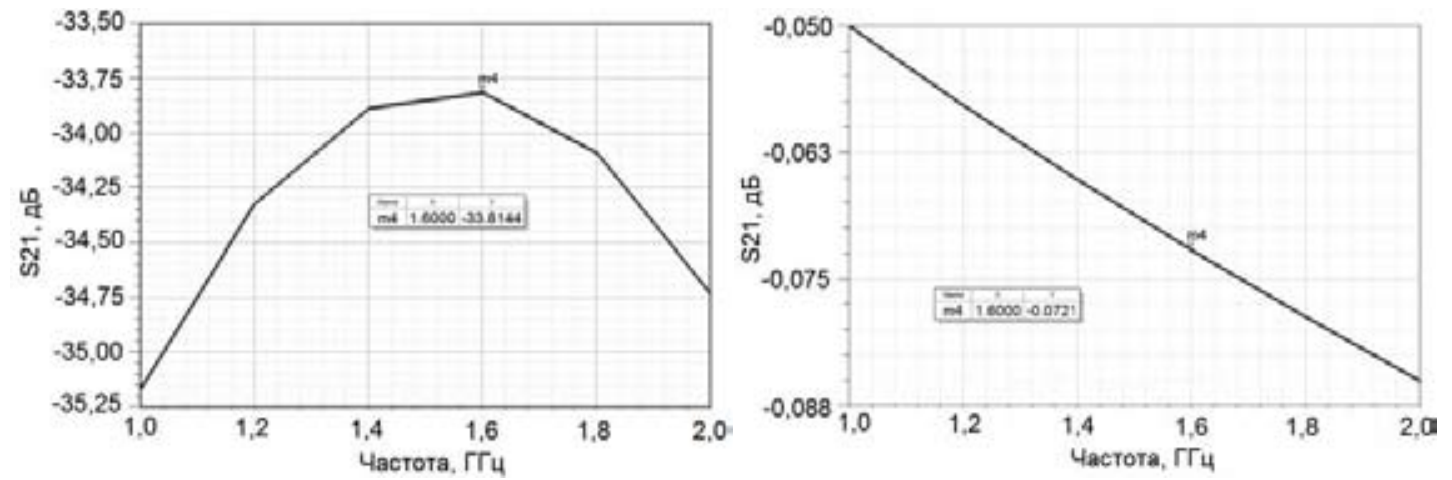

Рис. 7. S11- и S21-характеристики оптимизированного на частоту 1,6 ГГц резонатора на микрополосковой линии
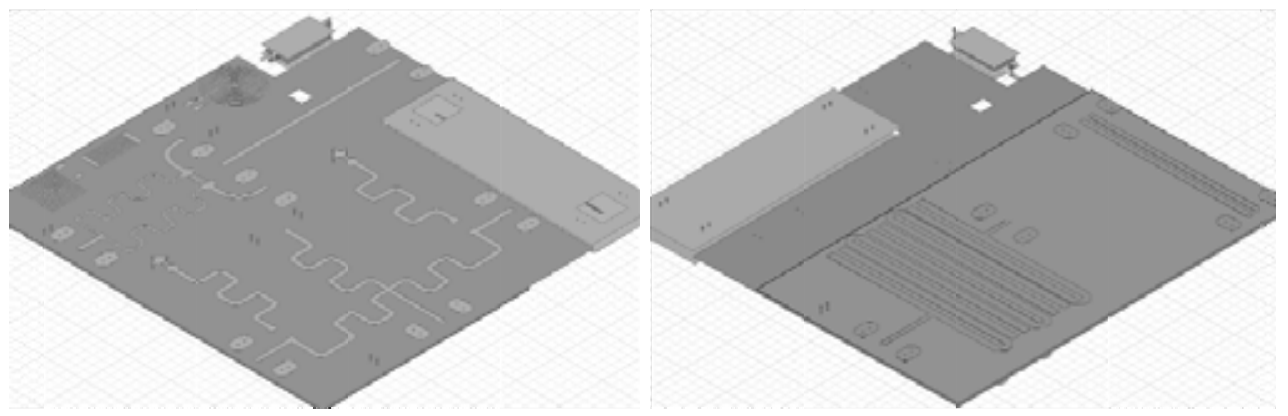

Рис. 8. Макетный образец СВЧ МИС НТК

полосно-пропускающего фильтра, конденсатор, резонатор, проведённое в данной работе на основе низкотемпературной совместно обжигаемой керамики, послужило базой разработки макетного образца многослойной интегральной схемы многоканального приёмника ГНССсигналов нового поколения: ГЛОНАCC, NAVSTAR GPS, Galileo и Compass L1-диапазона частот.

Полученные результаты работы впоследствии позволят вести: 1) расширение функциональных возможностей комплексированных аналоговых и цифроаналоговых трёхмерных СВЧ 
МИС НТК функционально насыщенных радиотехнических устройств и систем различного назначения за счёт интеграции пассивных компонентов между слоями с готовыми монолитноинтегральными схемами, элементами оптоэлектроники и акустоэлектроники; 2) повышение надёжности за счёт уменьшения паяных соединений и сокращения объёма ручной сборки; 3) улучшение комплексных физических (электрических, тепловых, механических) процессов, а также габаритно-массовых характеристик создаваемой аппаратуры.

\section{Список литературы}

[1] Сунцов С.Б., Алексеев В.П., Карабан В.М., Пономарев С.В. Прогнозирование надёжности узлов и блоков радиотехнических устройств космического назначения на основе моделирования напряженно-деформируемых состояний : монография Томск: ТУСУР, 2012. 114 с. [Suntsov S.B., Alekseyev V.P., Karaban V.M., Ponomarev S.V. Prognozirovaniye nadozhnosti uzlov i blokov radiotekhnicheskikh ustroystv kosmicheskogo naznacheniya na osnove modelirovaniya napryazhenno-deformiruyemykh sostoyaniy : monogr. Tomsk: TUSUR, 2012. 114 s. (in Russian)]

[2] Школьный В.Н., Сунцов С.Б., Карабан В.М., Дмитриев В.Д., Шеерман Ф.И. Разработка физической структуры многоканального приёмника сигналов ГНСС для автономного координатно-временного обеспечения искусственных спутников Земли. Известия вузов. Физика, 2015, 58(7), 114-121 [Shkol'nyi V.N., Suntsov S.B., Karaban V.M., Dmitriev V.D., Sheerman F.I. Razrabotka fizicheskoy struktury mnogokanal'nogo priyomnika signalov GNSS dlya avtonomnogo koordinatno-vremennogo obespecheniya iskusstvennykh sputnikov Zemli. Izvestiya vuzov. Fizika, 2015, 58(7), 114-121 (in Russian)]

[3] Shkol'nyi V.N., Suntsov S.B., Karaban V.M., Dmitriev V.D., Sheerman F.I. Development of the Physical Structure of a Multi-Channel GNSS Signal Detector for Autonomous Coordination and Time Support of Artificial Earth Satellites. Russian Physics Journal, 2015, 58(7), 1001-1009 [Школьный В.Н., Сунцов С.Б., Карабан В.М., Дмитриев В.Д., Шеерман Ф.И. Разработка физической структуры многоканального приёмника сигналов ГНСС для автономного координатно-временного обеспечения искусственных спутников Земли. Журнал русской физики, 2015, 58(7), 1001-1009 (in English)]

[4] Тюльпанов В. Особенности технологических процессов корпусирования. Электронные компоненты, 2011, №11, 14-19 [Tyul'panov V. Osobennosti tekhnologicheskikh protsessov korpusirovaniya. Elektronnyye komponenty, 2011, №11, 14-19 (in Russian)]

[5] Зырин И.Д., Карабан В.М. Разработка СВЧ-делителя мощности для радиоприёмного модуля на основе низкотемпературной керамики, 24-я Международная Крымская конференция «СВЧ-техника и телекоммуникационные технологии» (КрыМиКо'2014), Севастополь, Крым, 2014, T.2, 582-583 [Zyrin I.D., Karaban V.M. Development of microwave power divider for radio module based on low-temperature cofired ceramics, 24th International Crimean Conference Microwave and Telecommunication Technology (CriMiCo 2014), Sevastopol, Crimea, 2014, V.2, 582583 (in Russian)]

[6] Зырин И.Д., Карабан В.М. Разработка СВЧ-фильтра для радиоприёмного модуля на основе низкотемпературной керамики, 24-я Международная Крымская конферениия «СВЧ-техника и телекоммуникационные технологии» (КрыМиКо’2014), Севастополь, Крым, 2014, T.2, 586-587 [Zyrin I.D., Karaban V.M. Development of microwave filters for radio modules

$$
-521-
$$


based on low-temperatured cofired ceramics, 24th International Crimean Conference Microwave and Telecommunication Technology (CriMiCo 2014), Sevastopol, Crimea, 2014, V.2, 586-587 (in Russian)]

[7] Карабан В.М., Севастьянов Р.С., Герасимов Е.Г. Синтез пассивного полоснопропускающего фильтра для навигационных приёмников спутниковых систем, 24-я Международная Крымская конференция «СВЧ-техника и телекоммуникационные технологии» (КрыМиКо’2014), Севастополь, Крым, 2014, T.1, 304-305 [Karaban V.M., Sevastyanov R.S., Gerassimov E.G. The passive band passing filter synthesis for navigation receivers of satellite systems, 24th International Crimean Conference Microwave and Telecommunication Technology (CriMiCo 2014), Sevastopol, Crimea, 2014, V.1, 304-305 (in Russian)]

[8] Карабан В.М., Зырин И.Д. Разработка многослойной интегральной схемы полосового фильтра на основе макромоделей и эквивалентных схем RLC-элементов, 24-я Международная Крымская конференция «СВЧ-техника и телекоммуникаџионные технологии» (КрыМиКо’2014), Севастополь, Крым, 2014, T.1, 127-128 [Karaban V.M., Zyrin I.D. The multilayer integrated circuit of bandpass filter design based-on macromodels and equivalent circuits for RLC-elements, 24th International Crimean Conference Microwave and Telecommunication Technology (CriMiCo 2014), Sevastopol, Crimea, 2014, V.1, 127-128 (in Russian)]

[9] Зырин И.Д., Карабан В.М., Сунцов С.Б. Обзор возможностей математического моделирования шероховатости поверхности низкотемпературной керамики, 23-я Международная Крымская конференция «СВЧ-техника и телекоммуникационные технологии» (КрымиКо’2013), Севастополь, Крым, 2013, 181-182 [Zyrin I.D., Karaban V.M., Syncov S.B. Review of capabilities of mathematical models for surface roughness of the low-temperature ceramic circuit boards, $23 \mathrm{rd}$ International Crimean Conference Microwave and Telecommunication Technology (CriMiCo 2013), Sevastopol, Crimea, 2013, 181-182 (in Russian)]

[10] Карабан В.M., Зырин И.Д. Разработка эквивалентных схем интегральных RLCэлементов на основе LTCC, 24-я Международная Крымская конферениия «СВЧ-техника и телекоммуникационные технологии» (КрымиКо'2014), Севастополь, Крым, 2014, Т.2, 655-656 [Karaban V.M., Zyrin I.D. Synthesis of equivalent circuits for embedded RLC-components basedon LTCC, 24th International Crimean Conference Microwave and Telecommunication Technology (CriMiCo 2014), Sevastopol, Crimea, 2014, V.2, 655-656 (in Russian)]

[11] Сунцов С.Б., Карабан В.М., Климкин О.А., Зырин И.Д., Севастьянов Р.С., Краюхин А.С. Обзор возможностей систем автоматизированного проектирования для схемотехнического и топологического моделирования радиоэлектронной аппаратуры : моногр. Томск: ТУСУР, 2013. 86 c. [Suntsov S.B., Karaban V.M., Klimkin O.A., Zyrin I.D., Sevast'yanov R.S., Krayukhin A.S. Obzor vozmozhnostey sistem avtomatizirovannogo proyektirovaniya dlya skhemotekhnicheskogo i topologicheskogo modelirovaniya radioelektronnoy apparatury : monogr. Tomsk: TUSUR, 2013. $86 \mathrm{~s}$. (in Russian)] 